\title{
Liquefaction-Induced Ground Deformations Evaluation Based on Cone Penetration Tests (CPT)
}

\author{
Alketa Ndoj, Neritan Shkodrani, Veronika Hajdari \\ Department of Civil Engineering, Polytechnic University of Tirana, Tirana, Albania \\ Email: alketandoj@yahoo.com \\ Received 17 July 2014; revised 3 September 2014; accepted 20 September 2014 \\ Copyright (C) 2014 by authors and Scientific Research Publishing Inc. \\ This work is licensed under the Creative Commons Attribution International License (CC BY). \\ http://creativecommons.org/licenses/by/4.0/ \\ c) (i) Open Access
}

\begin{abstract}
The aim of this paper is to evaluate the liquefaction-induced ground deformations of sand-like soils based on Cone Penetration Tests (CPT) at Semani site, Fieri prefecture in Albania. These tests are performed during the process of investigation of this area, in which a Liquid Natural Gas Terminal-Power Plant was supposed to be built. This paper presents the assessment of the liquefaction and of the liquefaction-induced ground deformations such as lateral spreading displacement and post-liquefaction reconsolidation settlement. The liquefaction-induced lateral spreading and post-liquefaction reconsolidation settlement are estimated based on CPT data according to the method in MNO-12 "soil liquefaction during earthquake", presented by Idriss and Boulanger (2008). This evaluation is very important and should be taken into consideration for the design of engineering structures that will be constructed in this area. All the calculation's results are shown in graphs. At the end, there are highlighted some conclusions regarding the liquefaction-induced ground deformations in this site.
\end{abstract}

\section{Keywords}

Liquefaction, Cone Penetration Test, Lateral Spreading, Settlement, Factor of Safety

\section{Introduction}

The study area is located in the South Western part of the Hoxhara village, Fieri prefecture, near the Adriatic Coastline as shown in Figure 1. A subsurface investigation, which includes 12 SPT borings and 12 CPT soundings up to $25 \mathrm{~m}$ is performed in the site, where a Liquid Natural Gas Terminal-Power Plant is planned to be constructed. According to the geotechnical study, the deposits of quaternary present in the zone have a thickness of

How to cite this paper: Ndoj, A., Shkodrani, N. and Hajdari, V. (2014) Liquefaction-Induced Ground Deformations Evaluation Based on Cone Penetration Tests (CPT). World Journal of Engineering and Technology, 2, 249-259. 


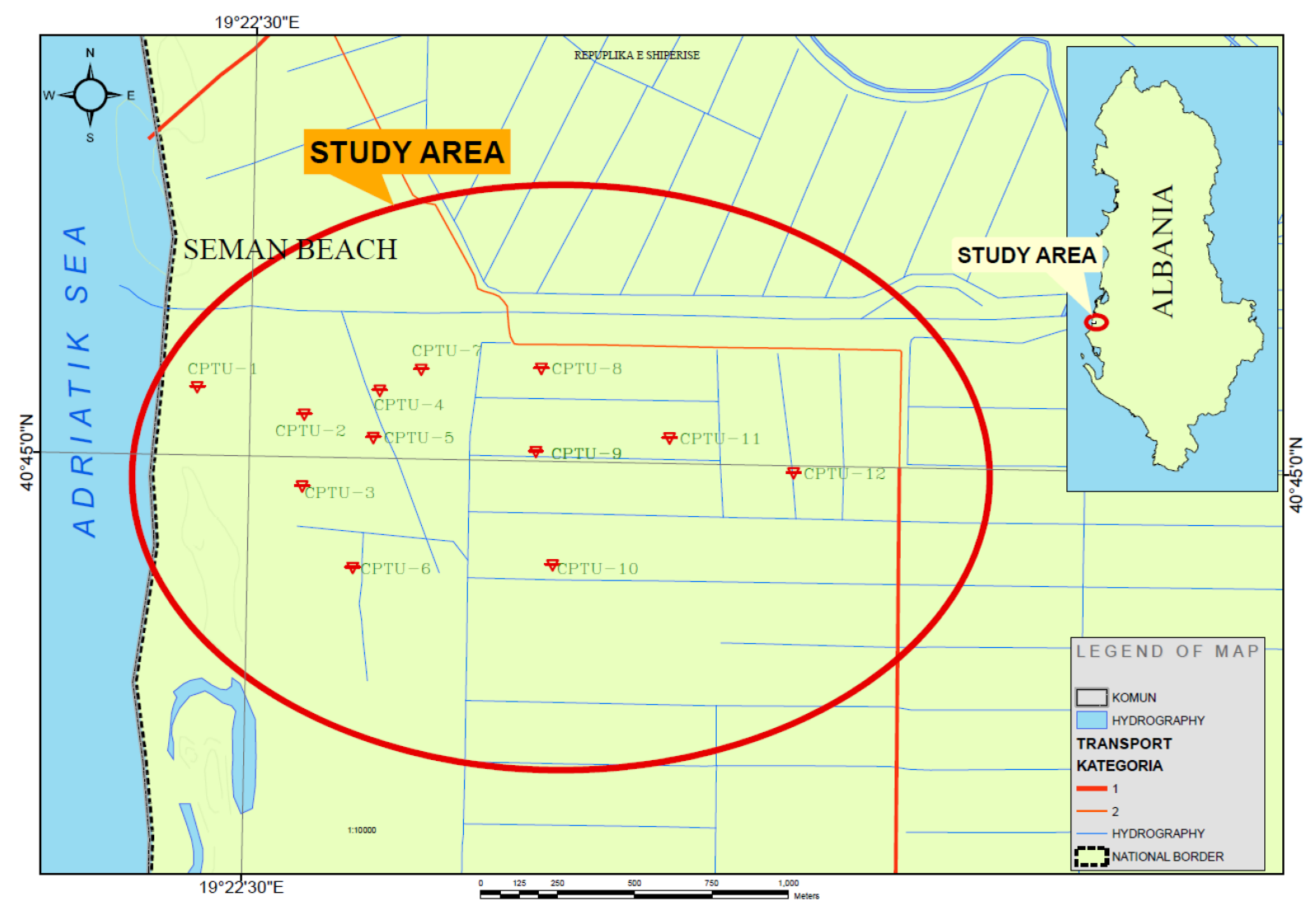

Figure 1. Geographic location of the study area.

more than $100 \mathrm{~m}$. These deposits are represented by gravels, sands, silty sands, silty clays, and clays. The water table is $0.5 \mathrm{~m}$ to $1.5 \mathrm{~m}$ from the ground surface [1].

Area of Semaniis included in the Periadriatic Depression, strongly affected by post-Pliocene compression movements (here in after referred as PL-zone), wherein have been recorded numerous strong earthquakes. This one is characterized by high seismic activity.

According to Albanian Earthquake-Resistant Design Regulation KTP-N.2-89, the soil conditions in this area are classified as Category III. The Peak Ground Acceleration, $a_{\max }$ for soil Category III, according to Shkodrani, et al. 2010 is $0.26 \mathrm{~g}$ [2].

The highest magnitude recorded up to date is Ms = 6.2 during the Fier earthquake of 18th of March 1962, according to Sulstarova, et al., 2010. During this earthquake were seen the liquefaction phenomena and its consequences including ground settlement, lateral spreading and sands boil [3].

Analysis of the factors that control the liquefaction indicates that the soils in this site are susceptible to liquefaction. The design of engineering structures that will be constructed in this area requires evaluation of the liquefaction and after that evaluation of the liquefaction-induced ground deformations. Different authors, such as Robertson and Wride 1998, Idriss and Boulanger 2008, Andrus and Stokoe 2000, have evaluated the liquefaction resistance of soil based on Standard Penetration Tests (here in after referred as SPT), Cone Penetration Tests (here in after referred as CPT), Shear Wave Velocity (here in after referred as Vs) data. The liquefactioninduced ground deformations can be evaluated based on the methods presented by Ishihara and Yoshimine 1992 and improved by different authors such as Zhang et al., 2004, Yoshimine 2006; Idriss and Boulanger 2008; Fred Yi 2010 for application to SPT, CPT, Vs data.

In this study these evaluations are conducted using 12 Cone Penetration Tests executed in this area by means of the equations presented by Idriss and Boulanger 2008.

The procedure of calculation includes the following steps:

1) Evaluation of the liquefaction potential based on CPT method presented by Idriss and Boulanger 2008; 
2) Calculation of the maximum shear strain $\gamma_{\max }$ and the post-liquefaction reconsolidation strain $\varepsilon_{v}$ based on Ishihara and Yoshimine 1992, Yoshimine 2006 with the additional constraint of a limiting shear strain presented by Idriss and Boulanger 2008;

3) Calculation of the lateral spreading and of the post-liquefaction reconsolidation settlement according to Idriss and Boulanger 2008.

Using the Simplified Procedure presented by Seed and Idriss 1971, the liquefaction is estimated based on the factor of safety against the triggering of liquefaction. The lateral spreading displacement and post-liquefaction reconsolidation settlement are calculated based on the maximum shear strain $\gamma_{\max }$ and post-liquefaction reconsolidation strain $\varepsilon_{v}$, respectively using CPT results. All the results of calculation are presented in graphs.

\section{Methodology}

The liquefaction-induced lateral spreading and post-liquefaction reconsolidation settlement for saturated clean sands and silty sands are estimated based on CPT data according to the presented method in MNO-12, "Soil liquefaction during earthquake”, Idriss and Boulanger, 2008 [4]. The soil behavior type index, Ic, as defined by Robertson and Wride (1998) is used to identify the liquefiable layers of the area from the CPT data [5].

Primarily the liquefaction potential based on Idriss and Boulanger 2008, is evaluated using the factor of safety against the triggering of liquefaction. Daja, et al., 2011 have also evaluated the potential of liquefaction in this area by means of the liquefaction probability. Comparing the results of these two methods is one of the aims of the paper.

Liquefaction estimation requires the evaluation of cyclic stress ratio and of cyclic resistance ratio. Cyclic stress ratiois evaluated according to Seed-Idriss Simplified Procedure using the calculated stress reduction coefficient based on the relation presented by Idriss, 1999 as a function of the depth and the highest earthquake recorded to date in study area $(M s=6.2)$. Cyclic Resistance Ratio is calculated as a function of three parameters: 1$)$ Equivalent clean-sand CPT penetration resistance that is used to account for the effects of nonplastic fines content on the liquefaction resistance; 2) Magnitude scaling factor MSF, calculated according to Idriss, 1999 based on the number of equivalent uniform stress cycles and earthquake magnitude; 3) Over burden correction factor, $K_{\sigma}$ calculated according to Idriss and Boulanger 2004, as a function of the corrected penetration resistance.

After that the lateral spreading displacement and post-liquefaction reconsolidation settlement are calculated based on the maximum shear strain $\gamma_{\max }$ and post-liquefaction reconsolidation strain $\varepsilon_{v}$, respectively. The maximum shear strain is calculated based on Ishihara and Yoshimine 1992 and Yoshimine 2006, as a function of the factor of safety against the triggering of liquefaction and of the limiting shear strain, expressed in terms of CPT penetration resistance. The post-liquefaction reconsolidation strain is also calculated based on Ishihara and Yoshimine 1992 and Yoshimine 2006, as a function of the maximum shear strain and of the CPT penetration resistance. All the results of calculations for factor of safety, post-liquefaction reconsolidation strain, post-liquefaction reconsolidation settlement, maximum shear strain and for lateral spreading displacement are shown in graphs in the third section of the paper for 12 CPT executed in study area.

\subsection{Evaluation of Factor of Safety against the Triggering of Liquefaction}

The factor of safety against the triggering of liquefaction is defined as the ratio of cyclic resistance ratio $\left(C R R_{M, \sigma_{v c}^{\prime}}\right)$ that will cause liquefaction of the soil to cyclic stress ratio induced in the soil by the earthquake $\left(C S R_{M, \sigma_{v c}^{\prime}}\right)$.

\subsubsection{Cyclic Stress Ratio $\left(\operatorname{CSR}_{M, \sigma_{v c}^{\prime}}\right)$}

Cyclic Stress Ratio $\left(C S R_{M, \sigma_{v c}^{\prime}}\right)$ is estimated via the Seed-Idriss simplified procedure from a formula that incorporates ground surface acceleration, total and effective stresses in the soil and nonrigidity of the soil column [6]. The stress reduction coefficient $r_{d}$ is estimated as a function of the depth and earthquake magnitude based on the relation proposed by Idriss (1999) [7] as follows:

$$
r_{d}=\exp (\alpha(z)+\beta(z) M)
$$




$$
\begin{gathered}
\alpha(z)=-1.012-1.126 \sin ((z / 11.73)+5.133) \\
\beta(z)=0.106+0.118 \sin ((z / 11.28)+5.142)
\end{gathered}
$$

where $z=$ depth $\leq 20 \mathrm{~m} ; M=$ moment magnitude of the earthquake and the arguments inside the sine terms are in radians.

\subsubsection{Cyclic Resistance Ratio $\left(C R R_{M, \sigma_{v c}^{\prime}}\right)$}

Idriss and Boulanger (2004) derived the following correlation between CRR and penetration resistance for the CPT. This correlation is used to evaluate the triggering of liquefaction in clean sands and silty sands.

$$
C R R_{M=7.5, \sigma_{v c}^{\prime}=1}=\exp \left(\frac{q_{c 1 N c s}}{540}+\left(\frac{q_{c 1 N c s}}{67}\right)^{2}-\left(\frac{q_{c 1 N c s}}{80}\right)^{3}+\left(\frac{q_{c 1 N c s}}{114}\right)^{4}-3\right)
$$

where: $q_{c 1 N c s}=$ represents the equivalent clean-sand CPT penetration resistance and is used to account for the effects of non plastic fines content on the liquefaction resistance.

$$
\begin{gathered}
q_{c 1 N c s}=q_{c 1 N}+\Delta q_{c 1 N} \\
\Delta q_{c 1 N}=\left(5.4+q_{c 1 N} / 16\right) \cdot \exp \left(1.63+(9.7 /(F C+0.01))-(15.7 /(F C+0.01))^{2}\right)
\end{gathered}
$$

where:

$F C$ = fines content;

$q_{c 1 N}=$ the overburden corrected penetration resistance and is calculated by using an overburden correction factor $C_{N}$.

The factor $C_{N}$ is calculated based on the relation proposed by Liao and Whitman (1986) and modified by Idriss and Boulanger (2003b), expressed in terms of the overburden corrected penetration resistance [8]:

$$
C_{N}=\left(P_{a} / \sigma_{v c}^{\prime}\right)^{1.338-0.249\left(q_{c 1 N}\right)^{0.264}} \leq 1.7
$$

where: $q_{c 1 N}=21-254$.

The above correlation for CRR is applicable to $M=7.5$ and an effective overburden stress of $\sigma_{v c}^{\prime}=1 \mathrm{~atm}$. This is extended to other values of earthquake magnitude and effective overburden stress by using the correction factors $M S F$ and $K_{\sigma}$ [4].

$$
C R R_{M, \sigma_{v c}^{\prime}}=C R R_{M=7.5, \sigma_{v c}^{\prime}=1} \cdot M S F \cdot K_{\sigma}
$$

where:

$M S F$ = magnitude scaling factor, given by Idriss (1999) based on the number of equivalent uniform stress cycles and earthquake magnitude:

$$
M S F=6.9 \exp (-M / 4)-0.058 \leq 1.8
$$

where:

$K_{\sigma}=$ overburden correction factor and is used to account for the overburden pressures on the liquefaction resistance.

It is calculated based on the relation given by Idriss and Boulanger (2004) [8], as follows:

$$
K_{\sigma}=1-C_{\sigma} \ln \left(\sigma_{v c}^{\prime} / P_{a}\right) \leq 1.1
$$

where:

The coefficient $C_{\sigma}$ is expressed in terms of the corrected penetration resistance as follow:

$$
C_{\sigma}=1 /\left(37.3-82.7\left(q_{c 1 N}\right)^{0.264}\right) \leq 0.3 ; q_{c 1 N} \leq 211
$$

\subsection{Maximum Shear Strain}

The maximum shear strain for a given factor of safety against liquefaction is estimated by combining expres- 
sions given by Yoshimine et al. (2006) with the additional constraint of a limiting shear strain as follow [4]:

$$
\begin{gathered}
\gamma_{\max }=\min \left(\gamma_{\text {lim }}, \frac{0.035\left(2-F S_{\text {liq }}\right)\left(1-F_{\alpha}\right)}{F S_{\text {liq }}-F_{\alpha}}\right) \text { if } 2>F S_{\text {liq }} \geq 2 \\
\gamma_{\text {max }}=\gamma_{\text {lim }} \text { if } F S_{\text {liq }} \leq F_{\alpha}
\end{gathered}
$$

where:

$\gamma_{l i m}=$ the limiting shear strain expressed as:

$$
\gamma_{\text {lim }}=1.859\left(2.163-0.478\left(q_{c 1 N c s}\right)^{0.264}\right)^{3} \geq 0
$$

where:

$F_{\alpha}=$ the limiting values of $F S_{\text {liq }}$ expressed as:

$$
F_{\alpha}=-11.74+8.34\left(q_{c 1 N c s}\right)^{0.264}-1.371\left(q_{c 1 N c s}\right)^{0.528}
$$

where: $q_{c 1 N c s} \geq 69$.

\section{Lateral Spreading Displacement}

Lateral displacement index, LDI suggested by Zhang et al. 2004 is calculated by integrating the maximum shear strains over the depth interval of concern.

The lateral displacement is calculated according to Zhang et al. 2004 [9].

$$
\mathrm{LD}=(S+0.2) * \mathrm{LDI}
$$

where:

$\mathrm{LD}=$ lateral displacement;

LDI = lateral displacement index;

$S=$ ground slope as a percentage.

\subsection{Post-Liquefaction Reconsolidation Strain}

Ishihara and Yoshimine (1992) observed that the volumetric strain that occurs during post-liquefaction reconsolidation of clean sands was related to $\gamma_{\max }$ developed during undrained cyclic loading and to relative density of the sand. $\varepsilon_{v}$ is estimated from the formulas expressed in terms of CPT penetration resistance as follow [4]:

$$
\varepsilon_{v}=1.5 \exp \left(2.551-1.147\left(q_{c 1 N c s}\right)^{0.264}\right) \cdot \min \left(0.08, \gamma_{\max }\right)
$$

where: $q_{c 1 N c s} \geq 21$.

\section{Post-Liquefaction Reconsolidation Settlement}

The ground surface settlement for one-dimensional reconsolidation is estimated by equating the vertical strains to the volumetric strains and then integrating the vertical strains over the depth interval of concern [4].

\section{Results}

The results of the calculations are presented below in graphs for $12 \mathrm{CPT}$.

\section{Discussions and Conclusions}

Factor of safety against liquefaction, liquefaction-induced maximum shear strain, lateral displacement index, lateral displacement, post-liquefaction reconsolidation strain and post-liquefaction reconsolidation settlement were calculated based on CPT data following the procedures presented in the previous sections. All the results are shown in Figures 2-5. 

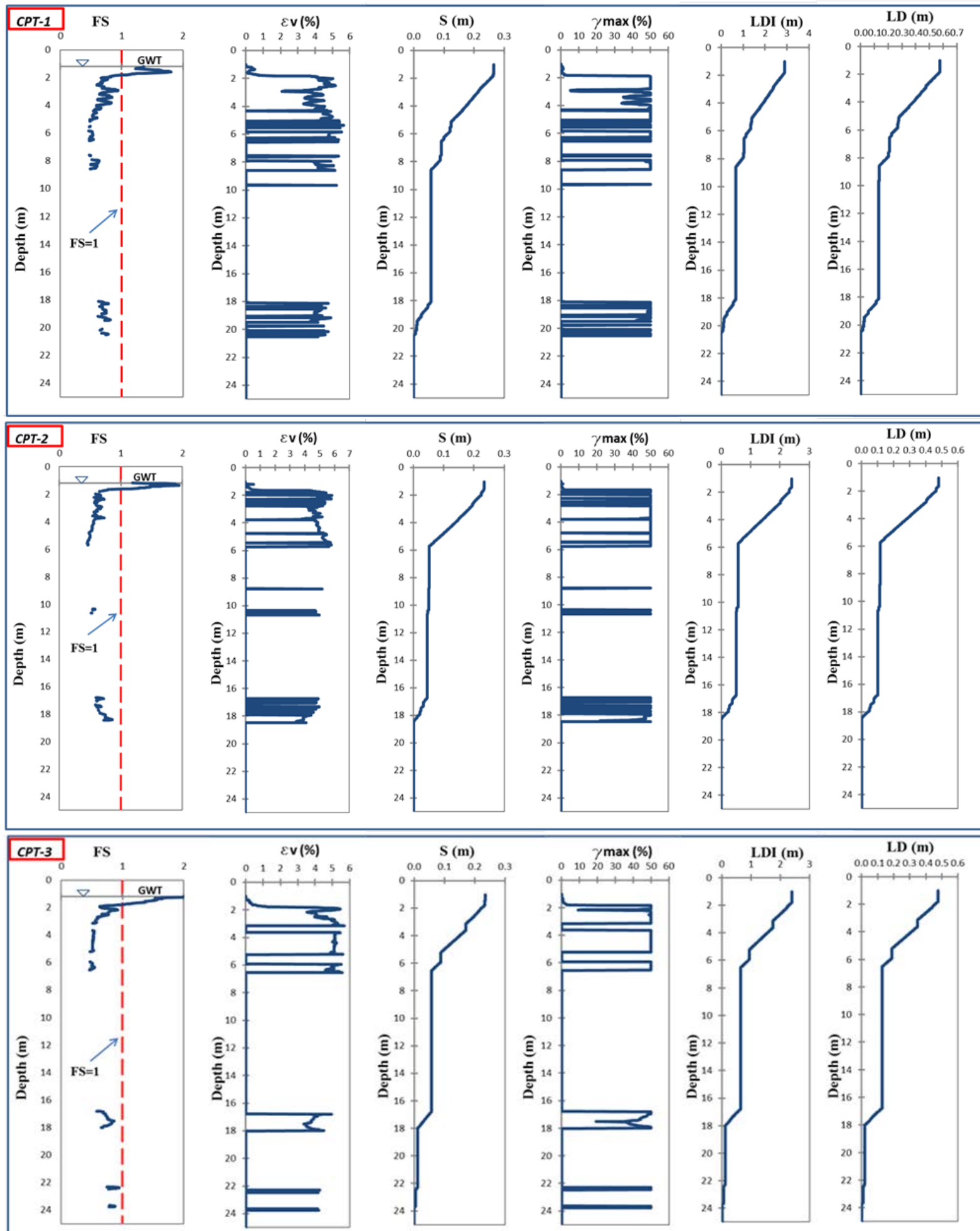

Figure 2. Evaluation of the liquefaction-induced lateral spreading and settlement in CPT-1, CPT-2 and CPT-3.

The analysis based on the factor of safety indicates liquefaction potential in this site. By comparing the results of this study with the results of the study of Daja et al. (2011) two intervals where the liquefaction is expected are almost at the same depth. The small differences might be due to the considered value of $I_{c}=2.8$ by Daja et al. 

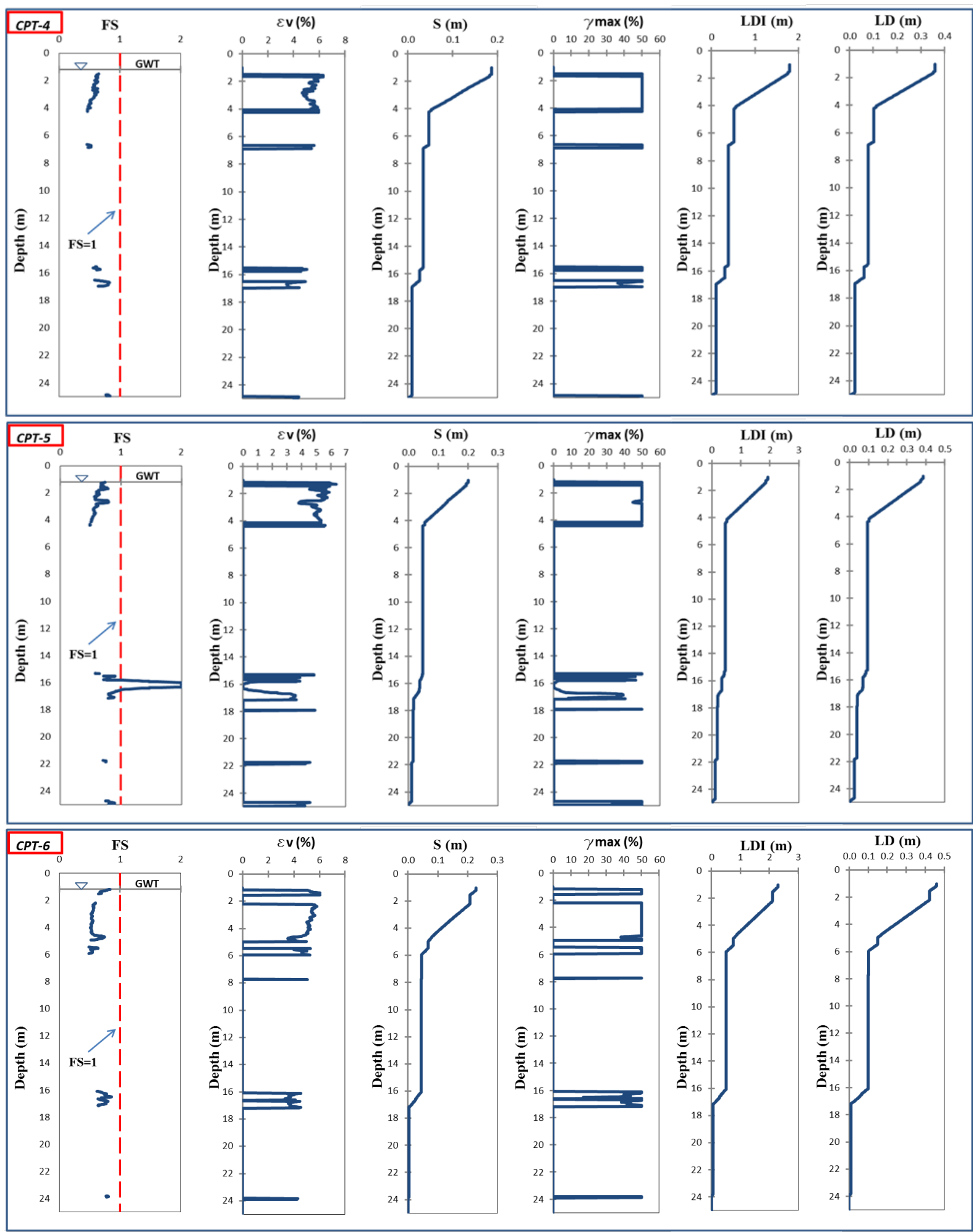

Figure 3. Evaluation of the liquefaction-induced lateral spreading and settlement in CPT-4, CPT-5 and CPT-6.

Lateral displacement index and post-liquefaction reconsolidation settlement are calculated as a function of the maximum shear strains. According to Idriss and Boulanger 2008, the maximum shear strains that occurs at low factor of safety against liquefaction tend toward limiting values that decrease as the relative density of the sand 

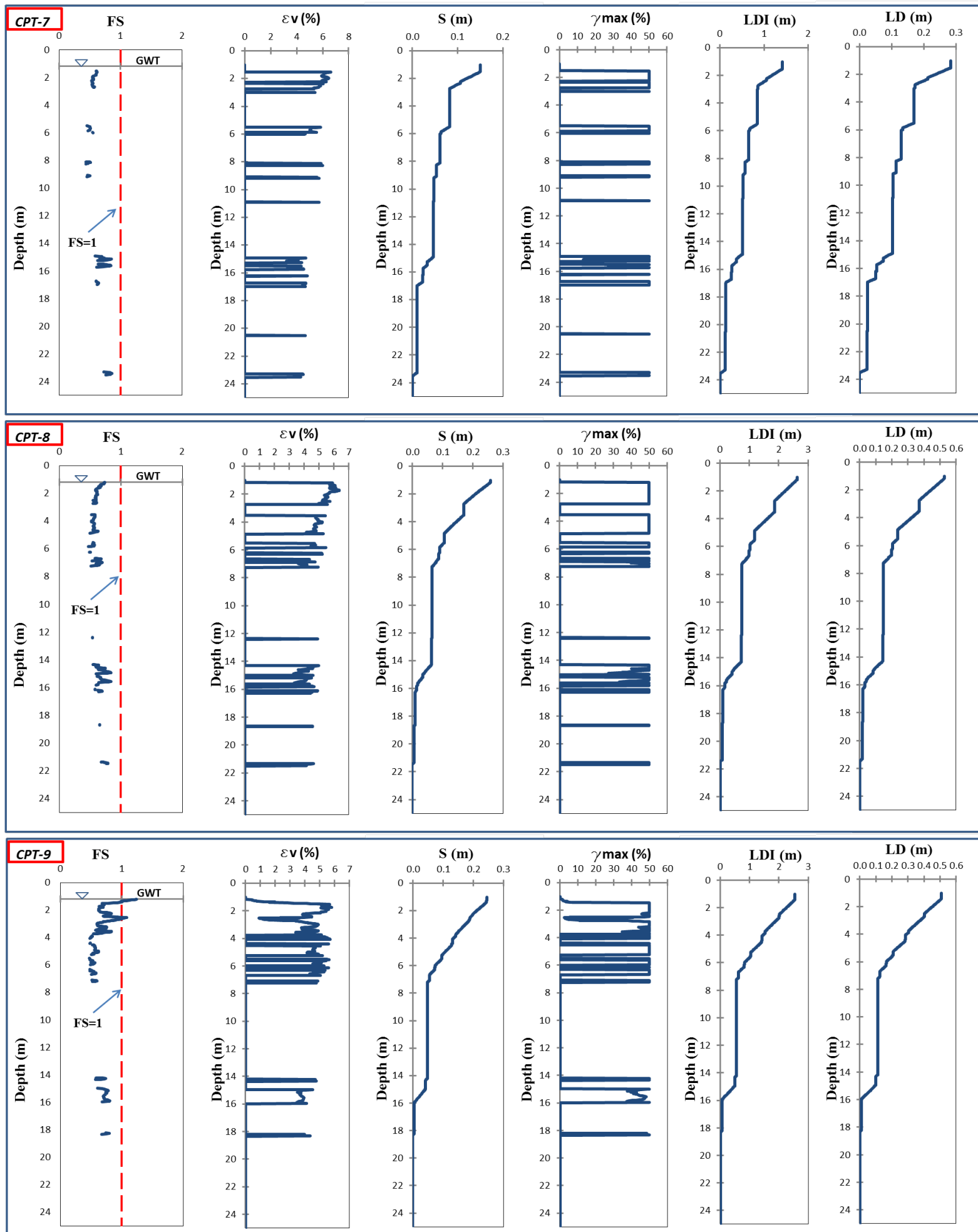

Figure 4. Evaluation of the liquefaction-induced lateral spreading and settlement in CPT-7, CPT-8 and CPT-9.

increases. The limiting shear strains are calculated as a function of the equivalent clean-sand CPT penetration resistance and are limited to about 50\% for computing LDI from individual soundings.

The calculated liquefaction-induced lateral spreading and settlement in this site are as follow: 

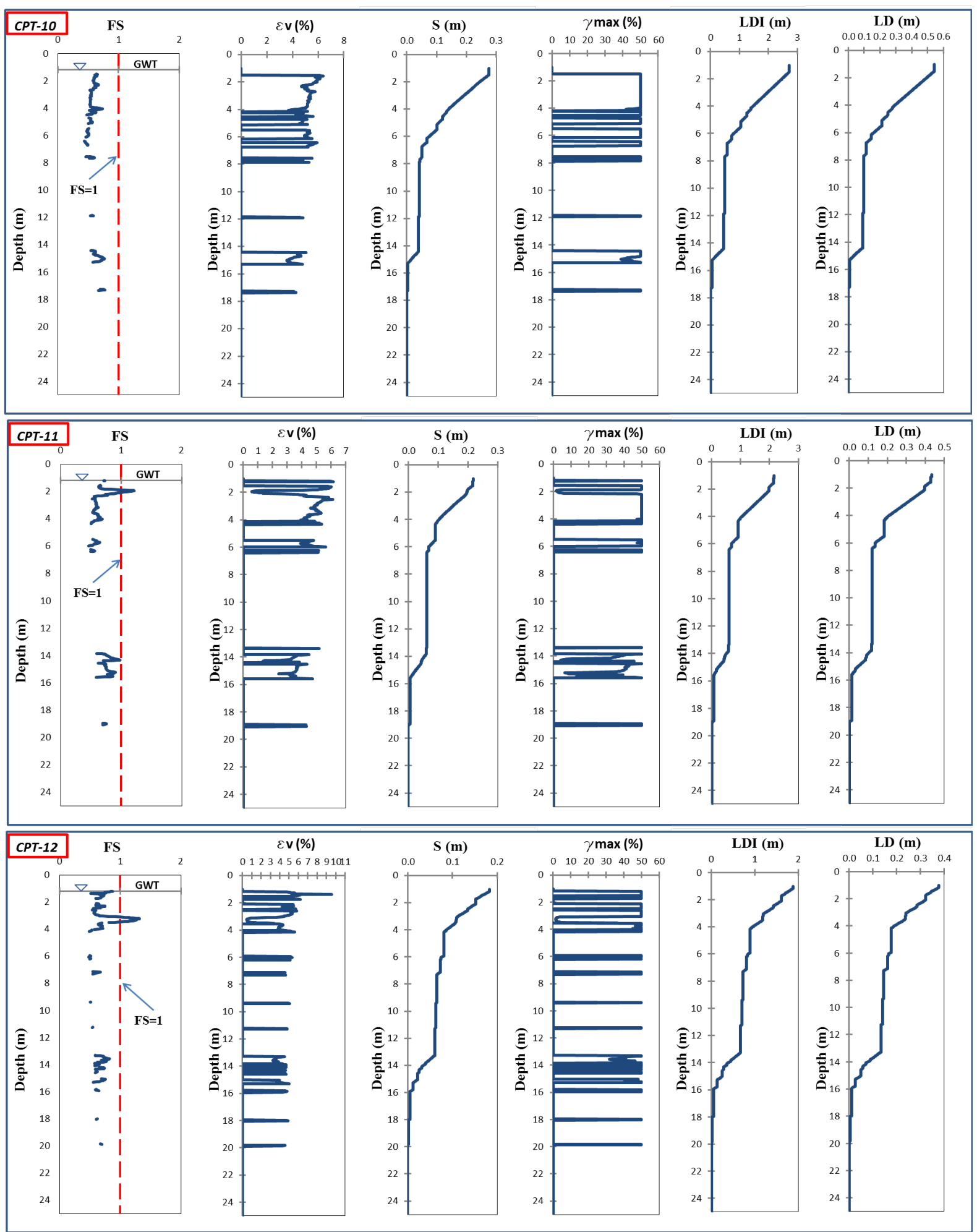

Figure 5. Evaluation of the liquefaction-induced lateral spreading and settlement in CPT-10, CPT-11and CPT-12.

Post-Liquefaction Reconsolidation Settlement: 0.15 m (CPT-7) up to 0.27 m (CPT-10);

Lateral displacement index: $1.42 \mathrm{~m}$ (CPT-7) up to $2.88 \mathrm{~m}$ (CPT-1);

Lateral displacement: $0.28 \mathrm{~m}$ (CPT-7) up to $0.57 \mathrm{~m}$ (CPT-1); 
These conclusions are very important for the design and construction of engineering structures in this site.

\section{References}

[1] Allkja, S. (2006) Geological-Engineering Conditions of Construction Site at P.N.G. Terminal-Power Plant Semani. Geotechnical Report, Tirana, 136.

[2] Shkodrani, N., Daja, S. and Ormeni, R. (2010) Engineering Characteristics of the Expected Shaking at Semani Site in Albania. ACEE-2010, Proceedings of the 3rd Asia Conference on Earthquake Engineering Disaster Risk Reduction and Capacity Building for Safer Environnment, Bangkok, 1-3 Decemeber 2010.

.http://www.ait.ac.th/news-and-events/2010/ait-in-the-news/may/3rd-asia-conference-on-earthquake-engineering/\#.VB oT7vmSxyU

[3] Aliaj, Sh., Koçiu, S., Muço, B. and Sultarova, E. (2010) Seismicity, Seismotectonis and Seismic Hazard Evaluation in Albania. Publication of Academy of Sciences, Tirana.

[4] Idriss, I.M. and Boulanger, R.W. (2008) Soil Liquefaction during Earthquake. EERI Publication, Monograph MNO-12, Earthquake Engineering Research Institute, Oakland. https://www.eeri.org/

[5] Robertson, P.K. (2010) Soil Behaviour Type from the CPT: An Update. 2nd International Symposium on Cone Penetration Testing, Huntington Beach, Vol. 2, 575-583. www.cpt10.com/PDF_Files/2-56RobSBT.pdf

[6] Seed, H.B. and Idriss, I.M. (1971) Simplified Procedure for Evaluating Soil Liquefaction Potential. Journal of the Soil Mechanics and Foundations Division, ASCE 97, SM9, 1249-1273.

[7] Idriss, I.M. (1999) An Update to the Seed-Idriss Simplified Procedure for Evaluating Liquefaction Potential. Proceedings of TRB Workshop on New Approaches to Liquefaction, Federal Highway Administration, Washington DC, 10 January 1999.

http://www.worldcat.org/title/proceedings-trb-workshop-on-new-approaches-to-liquefaction-january-1999/oclc/428895 $\underline{76}$

[8] Idriss, I.M. and Boulanger, R.W. (2003) Relating $K_{\alpha}$ and $K_{\sigma}$ to SPT Blow Count and to CPT Tip Resistance for Use in Evaluating Liquefaction Potential. Proceedings of the 20th Annual Conference of Association of State Dam Safety Officials, ASDSO, Lexington, 8-10 September 2003, 7-10.

http://scholar.google.com/citations?view op=view citation\&hl=en\&user=Z5HwZSMAAAAJ\&cstart=20\&pagesize=8 0\&citation for view=Z5HwZSMAAAAJ:TFP iSt0sucC

[9] Zhang, G., Robertson, P. and Brachman, R. (2004) Estimating Liquefaction-Induced Lateral Dispalcements Using the Standard Penetration Test or Cone Penetration Test. Journal of Geotechnical And Geoenvironmental Engineering, 130, 861-871. http://dx.doi.org/10.1061/(ASCE)1090-0241(2004)130:8(861) 


\section{Notation}

The following symbols are used in this paper:

$S P T=$ Standard Penetration Test

$C P T=$ Cone Penetration Test

$V_{s}=$ Shear Wave Velocity

$a_{\max }=$ peak ground acceleration

$F S_{\text {liq }}=$ factor of safety against the triggering of liquefaction

$C S R_{M, \sigma_{v c}^{\prime}}=$ cyclic stress ratio

$C R R_{M, \sigma_{v c}^{\prime}}=$ cyclic resistance ratio at a given earthquake magnitude and effective overburden stress

$C R R_{M=7.5, \sigma_{v c}^{\prime}=1}=$ cyclic resistance ratio for moment magnitude of the earthquake $M=7.5$ and effective over-

burden stress $\sigma_{v c}^{\prime}=1 \mathrm{~atm}$

$r_{d}=$ shear stress reduction coefficient to account for flexibility in soil profile

$M=$ moment magnitude of the earthquake

$q_{c 1 \text { Ncs }}=$ equivalent clean-sand CPT penetration resistance

$q_{c 1 N}=$ normalized over burden corrected CPT penetration resistance

$I_{c}=$ soil behavior type index

$F C=$ fines content

$C_{N}=$ over burden correction factor

$M S F=$ magnitude scaling factor

$K_{\sigma}=$ correction factor for soils layers subjected to large static normal stresses

$\gamma_{\max }=$ maximum amplitude of cyclic shear strain

$\gamma_{\text {lim }}=$ limiting value of shear strain

$F_{\alpha}=$ limiting values of $F S_{\text {liq }}$

$\mathrm{LD}=$ actuallateral displacement

$\mathrm{LDI}=$ lateral displacement index

$\varepsilon_{v}=$ post-liquefaction reconsolidation strain

$S=$ post-liquefaction reconsolidation settlement 
Scientific Research Publishing (SCIRP) is one of the largest Open Access journal publishers. It is currently publishing more than 200 open access, online, peer-reviewed journals covering a wide range of academic disciplines. SCIRP serves the worldwide academic communities and contributes to the progress and application of science with its publication.

Other selected journals from SCIRP are listed as below. Submit your manuscript to us via either submit@scirp.org or Online Submission Portal.
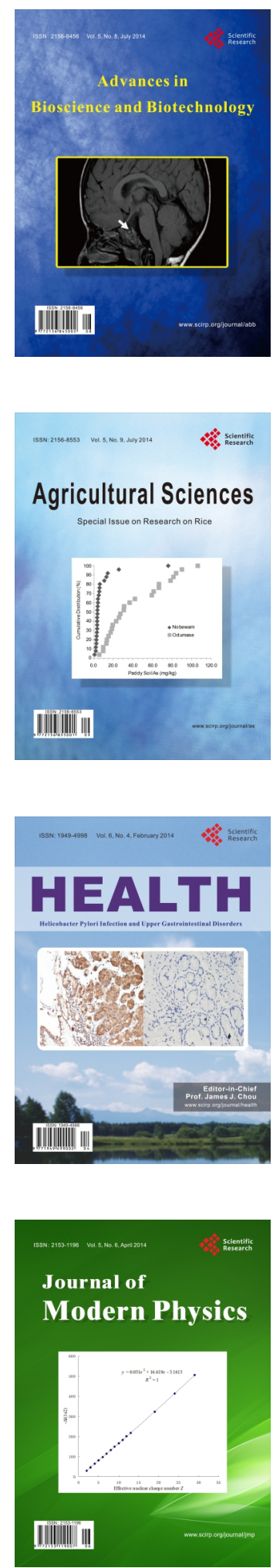
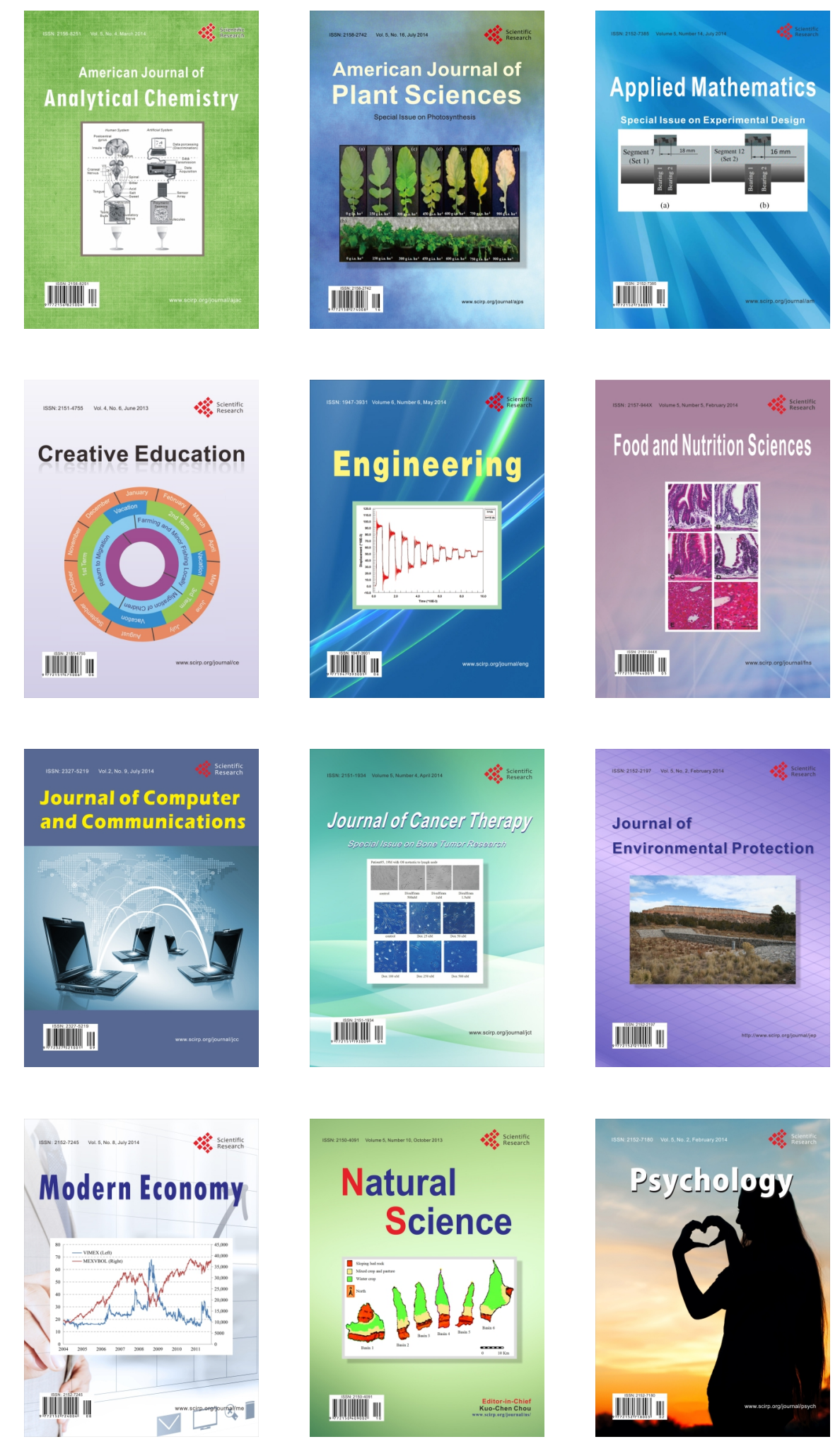